\title{
Effects of Nicotine on Sperm Health and Semen Quality: A Review based on Animal Studies
}

\section{Dibyendu Ray*}

Assistant Professor(Stage3) and Head, Environmental Toxicology and Reproductive Physiology Laboratory, Department of Physiology, Serampore College, 9 William Carey Road, Serampore, Hooghly-712201, West Bengal, India.

\begin{abstract}
Various studies have revealed the toxic effects of nicotine, an alkaloid compound of tobacco, on semen quality and sperm phys iology; however, these studies collectively are still unsummarized. Here, I systematically discuss and summarize the nicotine exposure, pharmacology and its insults on semen quality and sperm physiology. I searched the Web of Science, PubMed, and Scopus databases for only English language articles or abstracts from September 1969 to March 2019 (inclusive) using the key words "Nicotine" and "tobacco" versus "sperm". In conclusion, the mainstream published work demonstrates the negative effects of nicotine on semen quality: first, by increasing sperm count, a nd by enhancing sperm motility and reducing sperm DNA damage, though there are a few in clinical studies that have deliberated some adverse effects. The detrimental effects of Nicotine on semen quality may be due to decreased functionality of reproductive organs, increased levels of oxidative damage to sperm, reduced amount of energy produced by spermatozoa. However, additional research, mainly clinical, is still needed to confirm these
\end{abstract}

Keywords: Nicotine; sperm; testicular damage; semen quality

Article Info: Received 04 July 2019; Review Completed 18 Aug 2019; Accepted 22 Aug 2019; Available online 30 Aug 2019

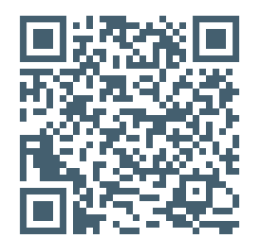

Cite this article as:

Ray D, Effects of Nicotine on Sperm Health and Semen Quality: A Review based on Animal Studies, Journal of Drug Delivery and Therapeutics. 2019; 9(4-A):754-758 http://dx.doi.org/10.22270/jddt.v9i4-A.3512

\section{*Address for Correspondence:}

Dibyendu Ray, Assistant Professor(Stage3) and Head, Environmental Toxicology and Reproductive Physiology Laboratory, Department of Physiology, Serampore College, 9 William Carey Road, Serampore, Hooghly-712201, West Bengal, India.

\section{Introduction:}

The WHO reports that approximately $8 \%$ of couples are infertile worldwide (WHO, 2008) and about 50\% of these infertility cases are related to male fertility factors. There is a significant relationship between smoking and infertility in men. Smoking exposes the body to more than 4000 chemicals among which nicotine is one of the main pharmacological, addictive substances which mimics most of the deleterious effects of cigarette smoke. Various studies on animal and human suggest that nicotine has an overall negative impact on conventional semen quality and semen parameters of smokers such as decreased sperm count, motility of the sperms, and overall increase in the number of abnormal sperms and therefore reduce reproductive outcome. It also is reported that chronic nicotine exposure reduces fertilizing potential by lowering spermatogenic cells, sperm count and motility, in dose- and time-dependent manner.

Nicotine and its metabolite cotinine act more complicated in male reproduction system. Chronic nicotine exposure has been positively correlated to lower plasma testosterone concentration. It has now been well established that nicotine-induced reductions of sperm production, maturation and fertilizing potential in rats were accompanied by a decrease in testosterone.

However, the mechanism by which nicotine causes male infertility is poorly understood. Some studies have revealed that nicotine can damage the male reproductive system through various means including oxidative stress, which is a primary factor in the pathogenesis of male infertility. There has been strong positive correlation among nicotine exposure and development of testicular and seminal oxidative stress. In fact, chronic exposure of nicotine, which act as both oxidant which act as both oxidant and prooxidant impairs homeostasis of the testicular oxidant and antioxidant enzymes.

\section{Origin of Nicotine:}

Nicotine (NIC) is the main hazardous component of cigarette smoke. It is a naturally occurring volatile-alkaloid, primarily found in plant of the Solanaceae family, which includes tobacco, potato, tomato, green pepper, and eggplant. German Physicians Wilhelm Heinrich and Karl Ludig Reimann first 
extracted nicotine from tobacco (Nicotiana tabacum). The major alkaloid is nicotine in commercial tobaccos which accounts for about $95 \%$ of the total alkaloid content [1]

\section{Physical and Chemical Properties:}

Nicotine is an amine, which is composed of pyridine and pyrrolidine rings. Nicotine, 3-(1-methyl-2-pyrrolidinyl) pyridine, is a volatile alkaloid with a molecular weight of 162.23. It is volatile base, colourless, water soluble and forms hydrosoluble salts [2]

\section{Chemical formula: C10H14N2}

\section{IUPAC name: 3-[2-(N-methylpyrrolidinyl)] pyridine}

Appearance: oily, colourless hygroscopic liquid, with characteristic odour, turns brown on exposure to air

Boiling point (decomposes): $247^{\circ} \mathrm{C}$

Density: $1.01 \mathrm{~g} \mathrm{~cm}-3$

Solubility in water: miscible

Vapour pressure at $20^{\circ} \mathrm{C}: 0.006 \mathrm{kPa}$

Octanol/water partition coefficient as log Pow: 1.2

\section{Exposure to Nicotine:}

\section{Global Scenario:}

Nicotine consumed with tobacco is probably the second most used drug in the world after caffeine from coffee and tea. It plays a central role in tobacco use and has been used by humans for thousands of years[3].It is reported to be one of the major hazardous components of tobacco which mimics most of the deleterious effects of cigarette smoke (Kavitharaj and Vijayamal, 1999). It has been used in many forms but often and more recently, at least in the Western world, almost only in smoked forms. Tobacco/nicotine is consumed regularly across all countries, cultures and almost all religions. Thirty-one (31\%) percent of men and $6 \%$ of women are tobacco users globally 2012[4]. Attributable burden due to tobacco smoking including second hand smoking was 6.3 million deaths and 156 million disabilityadjusted life year globally.

\section{Indian Scenario:}

India is the second largest consumer of tobacco where tobacco is used as smoked and smokeless tobacco (SLT).It has been reported that $28.6 \%$ of the Indian population consume tobacco in any form, $10.7 \%$ smoke, and $21.4 \%$ use SLT. Use of smokeless tobacco is documented in 120 countries, among them India has the largest number of SLT users in the world. Nearly one million people die every year in India due to tobacco use. Tobacco-related morbidity and mortality are high in the productive age group of 24 to 69 years. If, present trend continues, tobacco-associated mortality in India is estimated to be 1.5 million by 2020.India is a low- and middle-income country (LMIC) where tobacco related diseases increase financial burden and thus become a cause and consequence of poverty.

Nicotine exposure occurs in any or multiple of the following conditions:

- Personal exposure such as usage of any tobaccorelated product such as cigarettes, cigars, snuff and chewing tobacco(First hand smoking).

- So called 'second hand smoking' or passive smoking refers to the involuntary inhalation of tobacco by somebody else's who are present in close vicinity of first hand smokers.
- Occupational exposure during tobacco extraction or during making tobacco related product e,g cigarette.

- Environmental exposure as nicotine has been used as an insecticide in the past.

- Dietary exposure during consumption of tobacco containing edible foods like potato, green tomato etc. High level of nicotine in fresh potato and tomato products was reported by Siegmund et al. (1999) [5].

\section{Forms of Nicotine used:}

Followings are some means by which humans exposed to nicotine:

\section{Cigarettes}

A cigarette is a roll of tobacco. The most commonly thought of form of tobacco when you hear the word "smoking." Cigarettes include tobacco leaves, nicotine, and many cancer-causing chemicals. The smoke from a cigarette is inhaled into the lungs. Indians smoked about 6.2 cigarettes per day. Each cigarette contains considerable amount of it (10-14mg) and it is variable with brand[6]

\section{Cigars}

Cigars are another form of tobacco, they are tightly rolled, cured tobacco leaves in a leaf wrapper. Although cigars are usually not inhaled into the lungs, they still contain harmful, cancer-causing ingredients. Also, a cigar will have anywhere between 100 and $200 \mathrm{mg}$ of nicotine while an average cigarette contains $12 \mathrm{mg}$. They can also lead to a nicotine addiction.

\section{Bidis}

Bidis hail from India. They are hand-rolled and the tobacco is covered in a tendu or a temburni leaf that is native to Asia. bidis are accounted for the largest proportion of smoked tobacco consumed in India especially among the lower socio-economic group, they consume bidis is 8 to 10 times more than cigarette smoking. They contain 3 times more nicotine and 5 times more amount of tar than the regular cigarette.

\section{Electronic Cigarettes (e-cigarette)}

Electronic cigarettes or E-cigarettes is a newer kind of tobacco. This device, looking like a cigarette, cigar, or pen, have a liquid-filled container that holds variable concentrations of nicotine, flavouring, and other chemicals which may be harmful, and uses batteries to heat and create a vapour. The amount of nicotine in individual e-cigarette varies, although no tobacco smoke is produced. It is not yet known whether e-cigarettes are safe or not[7].

\section{Hookahs}

A hookah is a different form of tobacco - but is still just as dangerous. It is used to smoke flavored tobacco, which contains nicotine and cancer-causing chemicals. It is heated, then cooled by passing through a bowl of water, and the smoke is then inhaled through a mouthpiece. It can lead to addiction, and is not safer than smoking cigarettes.

\section{Chewing tobacco/ smokeless tobacco (SLT)}

Chewing tobacco is one of the most common methods of smokeless tobacco intake. This comes in the form of loose tobacco leaves, plugs, or twists. The nicotine distribution features of smokeless tobacco make it both addictive and a feasible substitute for cigarette smoking for many consumers, since it delivers a higher nicotine dose than other tobacco cessation products [8]. 
It can come sweetened and flavored, and is placed in the mouth between the cheek and lower lip. It can also be chewed. Although it is commonly thought that chewing is not as harmful, like the others, it contains nicotine and cancer-causing chemicals, and can also cause other health problems.

\section{Nicotine patches}

Nicotine patches and nicotine gum are commonly used as nicotine replacement therapy (NRT) for those who want to stop smoking. Since orally ingested nicotine is metabolized first in the liver, the bioavailability of swallowed nicotine medication is reduced [9].

Nicotine is also present in certain edible plants, especially plants from the family Solanaceae (potatoes, tomatoes) in the range of 2-7 microgram per kg of dry weight.

\section{Insecticides}

Nicotine has also been used as an insecticide since 17th century. However, after World War II, its use has declined owing to the availability of cheaper, more potent pesticides that are less harmful to mammals. The environment Protection Agency of United States has banned use of nicotine as a pesticide from 1st January 2014.India, one of the largest producer and exporter of nicotine sulphate, has progressively banned its use as agricultural pesticide. [APIB. Banned Pesticides. Available from: http://megapib.nic. in/Int_pest_bannedPest.htm. [Last updated on 2002 Mar 25; Last accessed on 2014 Sep 27].

\section{Pharmacology of Nicotine}

\section{Absorption:}

Nicotine absorption can occur through the lung, oral cavity, urinary bladder, gastrointestinal tract and skin[10]. It's absorption in human body is highly dependent on route of exposure and $\mathrm{pH}$. In acidic environments, it is in the ionized state and does not rapidly cross biological membranes. So nicotine is poorly absorbed from the stomach due to the acidity of the gastric fluid, but is well absorbed in the small intestine, which has a more alkaline $\mathrm{pH}$ and a large surface area[10].

At a high (alkaline) pH, nicotine remain as the non-ionized state, which passes more easily through lipoprotein membranes than the ionized (charged) state and be readily absorbed across the epithelium of the lung, the oral mucosa, and the nose, and through the skin.

\section{Bioavailability:}

The bioavailability of nicotine is route dependent with the highest about $90 \%$ when inhaled (e.g. cigarettes) and approximately $60 \%$ when used orally because of the huge surface area of the alveoli and dissolution of nicotine at physiological pH (approximately 7.4) and also because nicotine reaches the systemic circulation before passing through the liver where it is metabolized (first-pass metabolism) [11].

After absorption, It distributes extensively to body tissues, including the liver, kidney, spleen, lung, and brain and also accumulates in gastric juice and saliva, breast milk, skeletal muscle, and fetal serum and amniotic fluid [12].

\section{Metabolism of nicotine:}

Nicotine has a half-life of about 2 hours in the human body, during this time $70-80 \%$ absorbed nicotine is metabolized in the liver, mainly by CYP2A6, UDP-glucuronosyl transferase, and flavin-containing monooxygenase to cotinine and other metabolites[12] The metabolism takes place in two phases:

In phase I, microsomal oxidation of nicotine takes place via multiple pathway and lead formation of various metabolites like cotinine, nornicotine, demethyl cotinine, trans-3hydroxy-cotinine and $\delta$-(3- pyridyl)- $\gamma$-methylaminobutyric acid, N-oxidation and $\mathrm{N}$-methylation of nicotine, among which cotinine is the major metabolite and has a half-life of about 20 hours in the body.

In phase II metabolism, there is $\mathrm{N}$ - and $\mathrm{O}$-glucuronidation of nicotine and its metabolites[10]

\section{Lethal Dose:}

In experimental animals, the dose of nicotine which is lethal to $50 \%$ of the animals (LD50) varies widely, depending on the route of administration and the species used. (i.v.) The intraperitoneal (i.p.) LD50 values for nicotine in mice is 5.9 $\mathrm{mg} / \mathrm{kg}$ and in rats is $14.6 \mathrm{mg} / \mathrm{kg}$ [13].

In humans probable oral lethal dose is less than $5 \mathrm{mg} / \mathrm{kg}$ for a $70 \mathrm{~kg}$ person. It may be assumed that ingestion of $40 \mathrm{mg}$ to $60 \mathrm{mg}$ of nicotine is lethal to humans. (US-EPA. Chemical profile: Nicotine. US Environmental Protection Agency; 1987.)

\section{Mode of Action:}

As mentioned earlier that70 to $80 \%$ nicotine from inhaled smoke are absorbed and then metabolized in liver to six major metabolites. The fact that nicotine and its watersoluble metabolite cotinine are detectable in the seminal plasma of smokers and passive smokers exposed to environmental tobacco smoke[15]. Nicotine concentrations of between $70 \mu \mathrm{g} / \mathrm{l}(0.00043 \mathrm{mM})$ and $300 \mu \mathrm{g} / \mathrm{l}(0.00185 \mathrm{mM})$ are commonly found in the semen of casual (1-10 cigarettes/day) and habitual smokers ( $>30$ cigarettes/day) respectively [14].

This finding suggests that nicotine and other harmful components of tobacco smoke would pass through the blood-testis barrier[15] and activate nicotinic acetylcholine receptors (nAChRs) that result in various gonadotoxic effects on testes and male reproductive organs[16]

Nicotine binds to a class of ionotropic acetylcholine receptors, the "nicotinic receptors" (nAChRs) present in spermatozoa, made up of five subunits. In human spermatozoa, only 8 out of 16 nAChR sub units(namely $\alpha 1$, $\alpha 2, \alpha 3, \alpha 4, \alpha 5, \alpha 6, \alpha 7, a 9, \alpha 10, \beta 1, b 2, b 3, \beta 4, \gamma, \delta)$ are expressed. The different subunits form a large number of receptor isoforms, allowing a variety of different responses for each tissue.[16]

The mechanism by which nicotine exerts its toxic effects on testes is not clear. However various studies suggested that nicotine damages sperm function by interacting with nAchR on the cell surface of human spermatozoa. Over expression of $\alpha 7$ subunit is involved in the process of apoptosis, chromatin/DNA integrity, mitochondrial function and other sperm parameters [16].

\section{Adverse Effects on Male Reproductive System:}

\section{Effects of nicotine on sperm count /concentration} (Oligozoospermia)

According to WHO, male factor' infertility is generally involved an alteration in sperm concentration and/or motility and/or morphology in at least one sample of two sperm analyses, collected between 1 and 4 weeks apart [17]. 
The in vivo reproductive effects of nicotine have been assessed in many animal studies and most of them have reported nicotine adversely affect semen quality by reducing sperm concentration, alter morphology and by lowering sperm motility. Oligozoospermi, a medical condition characterized by low sperm count and quality, is responsible for $90 \%$ of male infertility[18].Several in vivo studies have indicated a significant reduction in the semen volume and sperm concentration in nicotine treated animals[1921].Nicotine and its metabolite cotinine easily enter into the blood circulation of testis and can have a direct cytotoxic effect on spermatozoa by damaging DNA[22].

\section{Effects of nicotine on sperm motility (Asthenozoospermia)}

Asthenozoospermia or reduced spermatozoa motility, may be an early indicator of reduced semen quality in smokers. Nicotine proved to be a potential oxidant which can affect spermatogenesis. Damage of membrane structure of the spermatozoa caused by nicotine is a major cause of the impaired motility [22-23].The seminal fluid of both smokers and passive smokers was found to contain nicotine at a concentration of $100 \mathrm{ng} / \mathrm{ml}$ and $10 \mathrm{ng} / \mathrm{ml}$ respectively which was able to suppress sperm motility by about $90 \%$ and may cause asthenozoospermia in smokers and non smokers[15,18 24]. In vitro studies also have indicated that the seminal nicotine, cotinine and trans-3'-hydroxycotinine levels were negatively correlated to total sperm motility $[15$, $18,25]$.

Effects of nicotine on sperm morphology (Teratozoospermia)

The incidence of teratozoospermia, or increased abnormal spermatozoal morphology, was also significantly higher in heavy smokers than in non-smokers [28]. Chronic smoke/ nicotine exposure has been positively correlated to increased abnormal morphology both in animals and humans studies[29]. Sepaniak et al. (2006) have reported that nicotine and its metabolite cotinine easily enter into the blood circulation of testis and can have a direct cytotoxic effect on spermatozoa by damaging DNA.

Table: Toxic Effects of Nicotine on Male Reproductive system

\begin{tabular}{|l|l|l|}
\hline Toxic Effects & Target & References \\
\hline $\begin{array}{l}\text { Decrease Testicular weight \& } \\
\text { degeneration of tissues }\end{array}$ & Germ cells, Sertoli/ Leydig cell & 22,2627 \\
\hline $\begin{array}{l}\text { Decrease Sperm parameters: } \\
\text { Sperm count, }\end{array}$ & $\begin{array}{l}\text { Sertoli/ Leydig cell } \\
\text { Function/spermatozoa }\end{array}$ & $15,1821-23$ \\
sperm morphomology & & \\
\hline Spermatogenesis & & \\
\hline Decrease Testosterone secretion & Leydig cell/ Sertoli cell & 19,22, \\
\hline
\end{tabular}

\section{Nicotine induces Oxidative stress: A possible mechanism of reproductive toxicity}

A possible mechanism underlying adverse nicotine-induced reproductive health outcome. However, the mechanism by which nicotine causes male infertility is poorly understood. There is considerable evidence from animal studies that exposure to nicotine can damage the male reproductive system through various means including oxidative stress, which may be a potential mechanism underlying deleterious nicotine-induced reproductive outcomes[23]. Indeed, adult animals exposed to nicotine exhibited increased ROS production and oxidative damage in the testes, which was associated with testicular damage (e.g., degeneration of seminiferous tubules, germ cell exfoliation, loss of Leydig cells, and disrupted spermatogenesis) and decreased sperm counts[19,22,26-27].

Nicotine increases ROS production by breaking the mitochondrial respiratory chain. A large number of experiments on rodent's(rats/mice) reflected that nicotine increased the production of $\mathrm{ROS}\left[\mathrm{H}_{2} \mathrm{O}_{2}\right.$ and hydroxylradicals $\left.\left(\mathrm{OH}^{-}\right)\right]$which has been associated with the induction of testicular oxidative stress[21-23].

Further studies also confirmed that nicotine reduces testicular /seminal antioxidant enzymes e.g CAT, SOD and glutathione reductase activity[19,21-23, 28] and this imbalance of ROS generation and oxidant enzymes lead to oxidative stress which may be a con-current mechanism of NT testicular toxicity and infertility.

\section{Conclusion:}

Thus far, the mainstream published studies (in vivo, or in vitro) present the negative effects of nicotine on semen quality in primarily decreasing sperm count and secondarily reducing sperm motility and increasing sperm DNA damage, though there are still a few in clinical studies that have deliberated some adverse/blunted effects.

However, further research-primarily clinical, is still necessary to confirm these adverse effects. At present, our laboratory is running an experimental study (in vivo) that uses different bio analytical methods, such as flow cytometry, to determine the mechanism of toxic action nicotine on reproductive system of male rats and its amelioration by vitamin B12 complex.

\section{Conflict of Interest}

The author declares that he has no conflict of interest

\section{References}

1. Jacob P 3rd, Yu L, Liang G, Shulgin AT, Benowitz NL (1993)Gas chromatographic-mass spectrometric method for determination of anabasine, anatabine and other tobacco alkaloids in urine of smokers and smokeless tobacco users. J Chromatogr 619:49-61

2. Sobkowiak R, Lesicki A.(2013) Absorption, metabolism and excretion of nicotine in humans. Postepy Biochem. 59:33-44

3. Wilbert, J. (1993). Tobacco and Shamanism in South America ISBN 0-300-05790-3.

4. Ng, M., Freeman, M. K., Fleming, T. D., Robinson, M., DwyerLindgren, L., Thomson, B. et al. (2014). Smoking prevalence and 
cigarette consumption in 187 countries, 1980-2012. Journal of American Medical Association, 311(2), 183-192.

5. Siegmund B, Leitner E, and Pfannhauser W (1999). Determination of the nicotine content of various edible nightshades (Solanaceae) and their products and estimation of the associated dietary nicotine intake. J Agric Food Chem. 47:31133120.

6. Pednekar M, Nagler E, Pawar P, et al (2016) The prevalence of tobacco use among manufacturing workers: findings from the baseline survey of Mumbai worksite tobacco control study. Prev Med.1:13.

7. Palazzolo DL. Electronic cigarettes and vaping: a new challenge in clinical medicine and public health. A literature review. Front Public Health. 2013 Nov 18;1:56)

8. Bates C, Fagerström K, Jarvis MJ, Kunze M, McNeill A, Ramström L.(2003) European Union policy on smokeless tobacco: a statement in favour of evidence based regulation for public health. Tob Control 12:360-7.

9. Stead LF, Perera R, Bullen C, Mant D, Hartmann-Boyce J, Cahill K, et al.(2012) Nicotine replacement therapy for smoking cessation. Cochrane Database Syst Rev 11:CD000146.

10. Yildiz D.(2004) Nicotine, its metabolism and an overview of its biological effects. Toxicon 43:619-32

11. Jacob P, Yu L, Liang G, Shulgin AT, Benowitz NL (1993)Gas chromatographic-mass spectrometric method for determination of anabasine, anatabine and other tobacco alkaloids in urine of smokers and smokeless tobacco users. J Chromatogr 619:49-61.

12. Benowitz NL, Hukkanen J, Jacob P (2009)Nicotine chemistry, metabolism, kinetics and biomarkers. Handbook of Experimental Pharmacology (192):29-60)

13. Gossel TA, Bricker JD (1994) Principles of Clinical Toxicology. 3rd ed. New York, NY: Raven Press.

14. Gandini L, Lambardo F, Lenzi A, Culasso F, Pacifici R, Zuccaro P, Dondero F(1997) The in vitro effects of nicotine and cotinine on sperm motility. Human Reprod.12(4):727-733.

15. Hassan A, Abo-Azma SM, Fayed SM, Mostafa T.(2008) Seminal plasma cotinine and insulin-like growth factor-I in idiopathic oligoasthenoteratozoospermic smokers. BJU Int. 103: 108-111.

16. Condorelli RA, La Vignera S, Giacone F, Iacoviello L, Vicari E, et al.(2013) In vitro effects of nicotine on sperm motility and bio-functional flow cytometry sperm parameters. Int J Immunopathol Pharmacol 26: 739-46.)
17. WHO(2008) Global Action Plan For The Prevention and Control of Diseases 2013-2030. Geneva.

18. Kumar, N.; Singh, A.K.(2015) Trends of male factor infertility, an important cause of infertility: A review of literature. J. Hum. Reprod. Sci. 8: 191-196.

19. Jana K, Samanta PK, De DK.(2010) Nicotine diminishes testicular gametogenesis, steroidogenesis, and steroidogenic acute regulatory protein expression in adult albino rats: possible influence on pituitary gonadotropins and alteration of testicular antioxidant status. Toxicol Sci 116:647-659.

20. Oyeyipo IP, Raji Y, Emikpe BO, Bolarinwa AF.(2011) Effects of nicotine on sperm characteristics and fertility profile in adult male rats: A possible role of cessation. J Reprod Infertil 12:2017.

21. Ray D, Bhattercharjee A, Majhi B, Mukherjee (2019) Amelioration of nicotine induced damges by Vitamin B12 and folic acid. J Biomed:

22. Dibyendu Ray, Mukherjee S( 2018) The Protective effects of chlorophytum borivilianum on Nicotine-induced reproductive toxicity, oxidative damage, histological changes and haematotoxicity in male rats JIPBS, Vol 5 (2), 76-81.

23. Sepaniak S, Forges T, Gerard H, Foliguet B, Bene M, MonnierBarbarino P. (2006)The influence of cigarette smoking on human sperm quality and DNA fragmentation. Toxicol. 223(1):54-60

24. Condorelli, R. A., La Vignera, S., Giacone, F., Iacoviello, L., Vicari, E., Mongioì, L., et al. (2013). In vitro effects of nicotine on sperm motility and bio-functional flow cytometry sperm parameters. Int. J. Immunopathol. Pharmacol. 26, 739-746.

25. Gandini L, Lambardo F, Lenzi A, Culasso F, Pacifici R, Zuccaro P, Dondero F(1997) The in vitro effects of nicotine and cotinine on sperm motility. Human Reprod.12(4):727-733.

26. Aydos K, Guven MC, Can B, Ergun A (2001) Nicotine toxicity to the ultrastructure of the testis in rats. BJU Int 88: 622-626

27. Nesseim WH, Haroun HS, Mostafa E, Youakim MF, Mostafa T.(2011) Effect of nicotine on spermatogenesis in adult albino rats. Andrologia 43: 398-404

28. Oyeyipo IP, Raji Y, Bolarinwa AF(2013) Nicotine alters male reproductive hormones in male albino rats: The role of cessation. J Hum Reprod Sci 6:40-44.

29. Rajpurkar A, Jiang Y, Dhabuwala CB, Dunbar JC, Li H (2002) Cigarette smoking induces apoptosis in rat testis. J Environ Pathol Toxicol Oncol 21:243-248 